\title{
The Problem with Impure Infinitism
}

\author{
HUSEIN INUSAH \\ University of Cape Coast, Cape Coast, Ghana
}

It is generally believed that pure versions of infinitism face two problems, namely: 1) they are unable to distinguish between potential and actual series of justified reasons because they are defined strictly in terms of relations between beliefs in the series so that every succeeding belief is justified by the belief before it and so on ad infinitum and, 2) they are unable to mark the difference between a set of justified reasons that are connected to truth and one that is not because they are defined strictly in terms of a relation between beliefs in the series of reasons. However, Aikin argues that impure infinitism could surmount these problems without undermining the infinite regress condition because impure infinitism can solve the Modus Ponens Reductio, MPR, argument that threatens pure versions of infinitism. I argue that Aikin does not succeed because his impure infinitism faces some fatal consequences and any attempt to salvage it will undermine the infinite regress of justification.

Keywords: Infinitism; impure infinitism; modus ponens reductio; justification; regress.

\section{Introduction}

Two problems ${ }^{1}$ confront what Aikin calls pure versions of infinitism. These are:

IP1: An infinite and non-repeating series of reasons cannot confer justification on a belief or cannot differentiate between an actual and a provisional set of justified reasons. In other words, an infinite series of reasons alone is not sufficient for justification.

${ }^{1}$ There are other problems of infinitism namely, the finite mind objection and the no-starting point objection and certain forms of the reductio problems (Klein 1999: 306ff). I take it that Klein's reply to these objections is convincing and proceed to look at these other two objections. 
IP2: There is no way to tell the connection between truth and justification in an infinite series of justified propositions. The point is that an infinite series of reasons alone is arbitrary because it is not properly connected to truth.

IP1 questions our intuition that if there are infinite series of justified propositions of which each justified proposition justifies its predecessor in the series, how is the terminating reason in the series justified? Put succinctly, what justifies the proposition terminating the series of regress of justification? An unjustified proposition cannot do the trick because it will imply one has to construct an infinite array of justified propositions on an arbitrary or unjustified proposition. ${ }^{2}$

IP2 suggests that an infinite series of justified reasons cannot account for the connection between justification and truth. For instance, let us consider a subject, $S$, having two sets of infinite and non-repeating series of justified beliefs supporting $p$ and $\sim \mathrm{p}$ respectively. Let's suppose that he claims that $p$ on the basis of $q$, and $q$ on the basis of $r$, and $r$ on the basis of $s$ and so on. Let's also suppose that she claims, on the same grounds, that $\sim p$ on the basis of $\sim q$ and $\sim q$ on the basis of $\sim$ $r$ and $\sim \mathrm{r}$ on the basis of $\sim s$ and so on. The problem is that, on the infinitist account, we lack the requisite resource to differentiate between the series of reasons that have a connection to truth and the one that has not. The assumption is that it is difficult to track the connection between justification and truth if one merely takes into consideration only the logical and the inferential connection between propositions in each set of the series. The standard proposal is that there should be some further conditions that when considered in addition to this inferential relation will mark out the connection between justification and truth. Otherwise, there is no way to adjudicate between these sets of propositions to ascertain which one has a connection to truth.

While IP1 is usually regarded as a conceptual problem for infinitism, IP2 is construed as an epistemic problem. ${ }^{3}$ Although IP1 and IP2 appear as distinct charges against infinitism, closer scrutiny reveals they are quite related to each other. IP1 suggests that an infinite array of justified propositions is not possible because such a series cannot differentiate between provisional and actual series of justified reasons. Any attempt to resolve this problem will require an additional resource that could undermine the infinite regress itself. IP2 rides on the back of IP1 in claiming that if IP1 be resolved, then it must be done in a way that reveals the connection between an infinite series of justified reasons and truth. Whereas Cling expresses pessimism as to how infinitism could resolve these two problems in tandem because to him

2 This problem is usually credited to J. Post's and J. Cornman's Modus Ponens Reductio argument of infinitism, according to which if an infinite series of reasons is organized in such a way that each member in the series is logically implied by its successor to produce justified beliefs, then no proposition in the series will be actually justified. See Post (1980: 9-10) and Cornman (1977: 290-299). It flows from this that any arbitrary chosen contingent proposition would be justified.

${ }^{3}$ The tags are due to Cling (2004: 107). 
any attempt "would undermine the rationale for the regress condition itself" (Cling 2004: 110), Aikin expresses optimism that these problems can be surmounted without undermining the regress condition necessary for justification in the infinitist scheme of things.

Aikin argues that an impure version of infinitism can circumvent both problems if it is couched to accommodate a foundationalist element of non-doxastic support to solve what he calls a Modus Ponens Reductio (MPR) argument against infinitism. He dubbed his version of infinitism 'strong impure infinitism' because his theory appeals to two sources of justification, which he thinks are individually necessary but insufficient for justification. This is unlike pure theories of justification that appeal to only one source of justification. So, an impure infinitist will hold that although the chain of justified reasons must be infinite and non-repeating, other formal principles of justification are legitimate (Aikin 2005: 199; 2008:178; 2011: 73).

Aikin uses justification trees (J-trees) to illustrate his position. Jtrees are graphic representations of reasons a subject holds for believing a proposition, say P. He argues that J-trees could have as many branches as possible, but it is necessary that at least one branch in every J-tree proceeds infinitely and that a basic belief is included in every J-tree. These basic beliefs are supposed to be non-doxastic. However, Aikin explains that beliefs on the J-tree are not entirely justified by non-doxastic content only because the justificatory status of these basic beliefs also requires inferential support (Aikin 2005: 200). Hence, he dubbed his theory strong impure infinitism (Aikin 2011: 75); as he notes, impure theories of justification are more "ecumenical" because they permit more than one standard source of justification (Aikin 2011: 73).

I argue that Aikin is not successful in this venture because if any effort is made towards resolving IP1 and 1P2, the result will undermine the infinite regress condition and sway strong impure infinitism from the core moorings of epistemic infinitism. I mount two defences in favour of my thesis. First, I peruse Aikin's classification of meta-epistemic theories of both foundationalism and epistemic infinitism and argue that other options within the infinitist's ken could generate a strong impure infinitism without necessarily invoking a foundational source of justification within a chain of infinite reasons. Second, I argue that although the MPR argument against pure infinitism succeeds on one account, on another account, it fails against pure versions of infinitism.

\section{A Misleading Taxonomy}

I shall devote this section to rehearse Aikin's analyses of various strands of meta-theories of justification. He notes four possible combinations of meta-epistemic theories for foundationalism and epistemic infinitism. I shall present only that of infinitism here for brevity purposes but may draw on that of the foundationalism for illustration purposes. 
Option 1: Strong, pure epistemic infinitism: the view that only infinite and non-repeating series of reasons is necessary and sufficient for justification.

Option 2: Strong impure epistemic infinitism: the view that an infinite and non-repeating series of reasons is necessary but insufficient for justification, thus other sources of justification are necessary. Option 3: Weak impure epistemic infinitism: the view that an infinite and non-repeating series of reasons could yield justification but are not necessary for justification.

Option 3 initially appears as a non-starter until recently Fredrik Herzberg defended a version of it. ${ }^{4}$ Given Aikin's account of infinitism, he favours option 2, an impure version of infinitism, which he says is analogous to strong impure foundationalism because it requires basic beliefs in addition to an infinite series of justification for a justification producing regress (Aikin 2008: 177ff). Furthermore, he assigns Klein and Fantl to option 1 because, according to him, they require that an infinite and non-repeating series of reasons as both necessary and sufficient conditions for justification producing regress (Aikin 2008: 177178). I have a strong reservation concerning the foregoing classification, not on Fantl (because Fantl has clarified Aikin's view of him in the review of the latter's 2011 book $)^{5}$ but on Klein. The fact that Klein is a pure infinitist is contestable though in some portions of his papers he sometimes alludes to the thesis that infinitism is committed to the idea that the structure of justificatory reasons is infinite and non-repeating. ${ }^{6}$ To be fair to Klein, he takes an infinite and non-repeating series of reasons to be a necessary but insufficient condition for a belief being justified for a subject; the propositions in the chain of reasons must also be available to the person (Klein 1999: 312). There must be another source of justification in addition to the infinite series of reasons for a proposition to be justified for a person on Klein's model of infinitism. This way of looking at the matter sits pretty well with option 2 , the idea that infinite and non-repeating series of reasons though necessary is insufficient for justification; so other sources of support is legitimate. Thus, by Aikin's approach, Klein's brand of pure infinitism is impure. ${ }^{7}$

${ }^{4}$ F. Herzberg has developed an account of coherentism and infinitism that synthesises the presence and strength of inferential support or connections with probabilistic consistency to generate a thesis he dubbed the dialectics of infinitism and coherentism. See Herzberg (2014).

${ }^{5}$ See footnote of (Aikin 2008: 181). Moreover, Fantl's version of infinitism does not specifically draw on the regress, so it is difficult to begin to pitch his brand of infinitism onto any of the options although Aikin does that. Meanwhile, Fantl has clarified this misconception in his review of Aikin 2011. See Fantl (2012).

${ }^{6}$ See Klein (1999: 297)

${ }^{7}$ One can also mount the same argument using the emergentist approach where Klein notes that there is an emergentist intervention in his approach of infinitism where justification emerges as the series of reasons widens (See Klein 2007: 8 and 2008: 494). 
Indeed, Aikin acknowledges Klein's idea of subjective availability of beliefs as a strategy for circumventing some reductio arguments but indicates that such intervention is different from his own (Aikin's) view. He avers the following, "my difference here is not with Klein's notion of belief, but with what supports those beliefs and in what way they may be dispositionally available to the subject" (Aikin 2005: 200). But this difference is so trivial to insulate Klein's brand of infinitism from occupying option 2. From the account offered above, what renders a theory impure is not the meta-justificatory challenge that it is likely to generate but whether it attracts individually necessary conditions as jointly sufficient for justification conferring regress.

Even if we stretch the argument, Klein's brand of infinitism could as well generate a meta-justificatory regress. For instance, if say a subject, S, utters the following expression: P: "I have hands" and proceeds to argue that the reason for $\mathrm{P}$ is subjectively available to her in the form of a dispositional belief, $\mathrm{Q}$ and that $\mathrm{Q}$ tentatively terminates the regress. A persistent interlocutor could demur by asking $\mathrm{S}$ why he thinks that $\mathrm{Q}$ can serve reasons for another proposition; or what makes Q assume that privileged epistemic status of rendering support to another proposition in the chain of reasons and so on. Here, the interlocutor could hold the infinitist accountable to their standards of ensuring epistemic responsibility. If the infinitist fails to answer this meta-justificatory challenge, then she endorses tacit foundationalism.

On the other hand, if she does, then she is a meta-justificatory infinitist. In the former case, the subject could be said to be an impure infinitist who is also a foundationalist at the meta-justificatory level. In the latter case, the subject is a thorough-going infinitist.

The lesson drawn from the above analysis is that Aikin's basis for rejecting Klein's version of meta-epistemic regress is not hinged on the reason that Klein's brand of infinitism is not impure. Instead, he rejects the meta-justificatory challenge that Klein's brand of infinitism could generate. But as noted, this should not be a basis for assuming that Klein promotes pure infinitism. Thus, Klein could be said to promote strong impure infinitism because, on the one hand, he allows that infinite and non-repeating series of reasons is necessary for justification and, on the other hand, he allows that subjective availability of reasons is necessary for justification. Both conditions are jointly sufficient for justification conferring regress.

But this does not immediately put the matter to rest. There is something clumsy about the label "strong impure infinitism." The reason is that pure theories of justification are exclusivist and, as Aikin notes, are committed "to the exclusivity of one source or formal structure of justification" (Aikin 2008: 175). Impure theories are not exclusivist and accommodate other sources of justification aside from their main structure of justification.

A theory is strong if the condition for a justification conferral regress is necessary but insufficient for justification. So for instance, 
strong foundationalism will be the view that basic beliefs are necessary for a justification conferral regress. Weak foundationalism will be the view that basic beliefs are not necessary for justification because other sources of justification may be legitimate. On this construal, pure theories of justification are strong because of their commitment to only one source of support in the structure. In a similar vein, weak theories are impure because they allow other sources of justification amongst propositions in the structure aside from the relevantly main source.

What about strong impure infinitism? The answer appears simple when looked at from Aikin's construal of infinitism. But this generates some unpalatable consequence as well. Aikin argues that his version of infinitism is strong because it is committed to the idea that noninferential series of reasons is necessary and productive of justification; yet it is impure because another source of justification is legitimate. It is refreshing to understand Aikin's strategy because he argues that his theory is not a dialectics of infinitism and foundationalism but an integrationist approach that integrates a non-doxastic component of foundationalism. He remarks: ... "this insight that drives foundationalism can be incorporated and appreciated in most meta-epistemic theories, and it certainly can work here" (Aikin 2005: 199).

The non-doxastic states, according to Aikin, "have justificatory purport only in the context of inferentially rich support, but that condition does not mitigate their own independent, non-inferential justification" (Aikin 2005: 200). This means that the non-doxastic support is incorporated not for justificatory purposes but something else because the infinitist structure of justification remains intact with the introduction of the non-doxastic support. This "something" else according to Aikin ensures that there is a connection between infinite and non-repeating series of reasons in a chain, on the one hand, and the external world, on the other, to mitigate the trouble of the isolation objection (the idea that justification structures that rely on only the relations between reasons as the criteria of justification isolate the belief system from the world because beliefs are not justified in virtue of relations beliefs and the external world). So, unlike just being a mixed theory of justification, Aikin's theory is also strong in that it allows that the infinite regress and the foundationalist non-doxastic support are individually necessary for justification. As Aikin himself notes "what impure theorists do with the piecemeal of intuitive cases of knowledge is cobble together a systematic view of knowledge that allows a variety of sources of justification" (Aikin 2008: 176). But this is not what his impure theory does. Although it does "cobble together" other sources of justification, only one source of justification is salient regarding the function apportioned to the non-doxastic support in the infinite structure of justification. So Aikin's impure view, in a sense, is not the same as Haack's foundherentism, which combines foundationalism and coherentism (Haack 1993); BonJour's weak foundationalism, which combines observational 
requirement into a coherentist structure (Bonjour 1985); or Herzberg, coherentism and infinitism which synthesises infinitism and coherentism (Herzberg 2014).

So, what does this bear on the prospects of Aikin's strong impure infinitism? The picture that we are presented with is that we have a brand of infinitism which focuses on the infinitist mode of justification (fitting pretty well into option 1) whose positive epistemic duty is to connect the entire chain of infinite reasons to the external world through the integration of non-doxastic support even though the regress condition undermines the non-inferential status of this non-doxastic input. So, there is an initial triumph over IP1; after all, it is not too stringently a problem, we can introduce another condition of justification as necessary without undermining the infinite regress of reasons.

What this means is that strong impure infinitism appears to miss its appropriate tag and qualifies to be placed in option 1 because, by the foregoing explication, it allows only inferential justification to be justification producing; the non-doxastic element only plays an epistemic role of allowing that an infinitist structure of justification possesses the relevant connection with the external world. In a similar vein, it qualifies to be slotted in option 2 because it introduces a further element in addition to the main infinitist condition of justification, the infinitist structure. The consequence appears to be that if Aikin's version of infinitism can be slotted in option 1 , then there could be an exciting twist to the story and this would be explored in what follows.

\section{The Modus Ponens Reduction}

From Aikin's point of view, impure infinitism has a dialectical advantage over pure infinitism because the latter cannot solve the modus ponens reductio. The modus ponens reductio, MPR, according to Aikin, is invoked to adjudicate between series of justified reasons that are truthconducive and those that are not. The argument is that an infinite chain of reasons is arbitrary when considered as a mere relation between beliefs. This is because there is no clear manner to adjudicate between a chain that is truth-conducive and one that is not. He remarks:

The MPR ...was simply that for any proposition, one could construct an infinite series of logically valid modus ponens inferences that support the proposition, and it turns out that a formally identical series can be constructed for the proposition's negation. The lesson was supposed to be that an infinite series of inferences cannot themselves distinguish between true and false propositions. (Aikin 2011: 105)

From Aikin's point of view, to circumvent this problem, basic beliefs are needed to distinguish between justified chains of beliefs that are truthconducive and those that are arbitrary. Hence, basic beliefs don't serve as regress enders but only play an epistemic role of marking out an infinite chain of reasons that is truth-conducive from one that is not (Aikin 
2005: 199; 2008: 183; 2011: 105). His strategy hinges on the assumption that basic beliefs possess non-doxastic support and this support does not mitigate their inferential role. On this construal, the reason why basic beliefs do not end the regress is that they only play the role of perceptual experience to indicate why a series of justified reasons is connected to truth: sensory experience provides our only acquaintance with the empirical world, so it provides the framework for our beliefs to match external reality. Hence, beliefs grounded in experience are more likely to be true because they map empirical reality.

The modus ponens reductio is at the heart of IP2, and the way Aikin resolves IP2 is by integrating a basic belief with non-doxastic support within an infinite series of inferential support. Aikin may be said to be right here. But he appears to argue that what he calls pure theories of infinitism, like Klein's and Fantl's versions, lack the resources to solve the modus ponens reductio. This is where I think Aikin is mistaken because Klein's strategy of invoking dispositionally available belief is to resolve the modus ponens reductio, albeit not exactly the way Aikin resolves it. Although Klein does not reply directly to the MPR argument against infinitism, one may draw on his strategy of dispositionally available belief to resolve this problem. Klein has replied John Post's reductio argument that if every proposition is justified by its successor, then for any contingent proposition, $p$, one can construct an instance of an infinite chain of regress. His reply was to suggest that the propositions in the chain must also be available to the subject. According to Klein, this way of looking at the issue does not place any constraint on the regress (Klein 1999: 312). This same strategy can be invoked to resolve the MPR. I am not holding brief for Klein, but I think that Klein has anticipated that any brand of infinitism will be vulnerable to the MPR if every contingent proposition and its negation are justified for the same person at the same time. But it will be fine if for a subject, $\mathrm{S}$, the proposition in the chain terminating in $\mathrm{p}$ is available and for another subject $S^{*}$ (where $S$ and $S^{*}$ are identical at different times or where $\mathrm{S}$ and $\mathrm{S}^{*}$ are not identical), the proposition terminating in $\sim p$ is subjectively available in the form of dispositional belief. This will not raise any problem because S's set of beliefs that are dispositionally available to her will be different from $\mathrm{S}^{*} \mathrm{~s}$ and there is no constraint on why $p$ shouldn't be justified for $S$ and $\sim p$ be justified for $\mathrm{S}^{*}$. Once we grant this explanation some credibility, then Aikin's argument that Klein's version of infinitism cannot adjudicate between a series of infinite reasons and its negation is not compelling. So, Klein's version of infinitism avoids the unpalatable situation where a chain of infinite and non-repeating series of reasons will support both $p$ and $\sim p$.

It may be objected that this way of resolving the MPR is not an adequate account for addressing IP2. I concede. So, Aikin might be right after all that Klein's versions of infinitism lead to IP2. But it will seem erroneous to assume that Klein's version is vulnerable to MPR; it is 
rather susceptible to the isolation objection problem. Put succinctly; it suffers from an epistemic problem of linking an infinite and non-repeating chain of reasons to the external world. The MPR and the isolation objection problem are not necessarily conjoined challenges against epistemic infinitism although there is a point of interdependence. An infinitist can resolve the MPR in another appropriate way and still may be troubled with the isolation objection problem as seen in Klein's intervention. But once the isolation objection problem is resolved, it is fixed in tandem with the MPR. The problem with Klein's version of infinitism is that it solves the MPR but falls shy at solving the isolation objection problem.

On the above showing, both Klein's and Aikin's positions appear to have chalked some initial success in the way they circumvent the IP1. The crux of IP1 is that one cannot introduce an additional source of justification in the regress of reasons without undermining the regress condition itself-meaning that one cannot introduce another source of justification in the chain of reasons and still be said of espousing infinitism. The challenge is that any theory that does so loses its moorings with epistemic infinitism. But have not Klein and Aikin show that one can achieve this feat and still be an infinitist?

Now, what is the prospect of both Klein's and Aikin's versions of infinitism on the account of IP2? I have already argued that Klein only resolves one part of the MPR and fails to resolve the other-the part that throws up the isolation objection problem. I will, therefore, focus only on Aikin's impure infinitism and how it attempts to circumvent IP2.

One of the remarkable tractions about impure infinitism as Aikin notes is that it "has the dialectical advantage over pure infinitism, because it can address the challenge of the "modus ponens reductio"" (Aikin 2008: 184). As noted earlier, once the isolation objection problem against infinitism is resolved, it also caters for the MPR. So, Aikin could be right that he has successfully resolved IP2. But the worry is that Aikin resolves IP2 in a way that makes his impure infinitism vulnerable to IP1.

Recall that with impure infinitism, Aikin notes that the non-doxastic support introduced into the chain of infinite reasons does not end the regress. In the same vein, the regress does not mitigate the independence of the non-inferential justification of this non-doxastic support. So, the regress is nonetheless infinite despite the non-inferential status of the non-doxastic support- a plausible scheme to ensure impure infinitism gets caught up in option 2. Any theory of infinitism deserving of the name, however assorted, must be a 'strong' infinitism (because it regards non-inferentiality as necessary for justification) otherwise it loses anchorage with the core tenets of epistemic infinitism. Aikin's does this manoeuvre remarkably well except his solution generates an unpalatable consequence for his brand of infinitism. The problem is that Aikin does not only advocate for the incorporation of non-doxastic 
support in an infinite series of justificatory reasons but also require it in addition to the infinite reasons to confer justification. That is to say, Aikin seems to say that the infinite and non-repeating set of reasons and the non-doxastic input are individually necessary conditions and both combined are necessary and sufficient conditions for justification. The foregoing, a fortiori, grounds his strong impure theory of justification.

This is what Aikin says about a justification conferring chain of infinite reasons: "Only infinite chains of reasons that integrate standing non-inferential input can confer justification" (Aikin 2014: 32). Henceforth, I shall refer to this as the justificatory conferring master statement for strong impure infinitism (JAA). Now, JAA seems to generate some unpalatable implications for impure infinitism. ${ }^{8}$ First, the explanation Aikin offers to buttress JAA runs contrary to his initial reasons for incorporating the non-doxastic support into an infinite series of reasons. Aikin writes:

Take these sort of arguments on analogy to the alternate systems arguments against coherentism: if formal relations between beliefs constitute justification, then couldn't one stipulate any series of beliefs with those formal relations, and thereby have justification? I have proposed one answer to this objection elsewhere, holding that other sources of non-inferential justification must work alongside these chains of reasons, which distinguish acceptable from unacceptable chains (and so, empirical evidence can determine which chain of reasons confers justification, and which one is merely hung in the air). (Aikin 2014: 32)

Aikin refers to two of his works (Aikin 2008 and 2009) and argues that he made a similar argument in those works. This is quite misleading because, in those works, Aikin had stated that the non-inferential support is meant to adjudicate between beliefs that are truth-conducive and those that are not in an infinite series of reasons. After all, the nondoxastic support does not end the regress (I have made this point earlier). How then does an infinite regress with non-doxastic support that does not end an infinite regress confer justification? How is justification conferred in an infinite series of reasons that incorporates non-doxastic support which does not end the regress of reasons?

Second, JAA appears to concede to IP2, but a concession to IP2 seems fatal to Aikin's infinitism because it undermines the regress of infinite justification and damages impure infinitism as a brand of infinitism. Aside from the concession to IP2, the idea itself raises questions because the infinite series of reasons and the non-doxastic support alone cannot confer justification without some other requirements counting in favour of a justification affording regress. What is the way out of this confusion? Three proposals are considered, and each is seen to deal a deadly blow to impure infinitism.

${ }^{8}$ Oakley noted one of these worries in his work. Refer to Oakley (2017). 
P1: The infinite regress, the non-doxastic support and a sort of transmission requirement may be considered as individually necessary and jointly sufficient condition for justification conferral.

P2: The infinite regress, the non-doxastic support and a kind of emergentist criteria are individually necessary and jointly sufficient for a justification affording regress.

P3: Each of the propositions in the infinite regress of reasons contains non-doxastic support for complete justification.

None of these proposals seems plausible. For instance, P1 will make the regress of reasons redundant because justification would be conferred to the other propositions in the series of reasons via the transmission requirement which could undermine the regress of justification. For instance, if the propositions in the chain, p, q, r, and t are justified because the series is infinite and the proposition $\mathrm{p}$ at the head of the series integrates a non-doxastic support, then there cannot be any justification conferral unless justification is transmitted from $p$ to the other beliefs in the series. Failure to endorse the transmission requirement in this context will amount to evading IP1. Alternatively, an endorsement of the transmission requirement will amount to a concession to IP1 which undermines the very regress of justification the infinitist hopes to promote.

In a similar vein, P2 will undermine the infinite regress of reasons. The assumption is that if the transmission conception is denied, then the impure infinitist can subscribe to the emergentist conception to prevent the theory from lapsing into foundationalism. Indeed, Aikin has opted for an emergentist view where he endorses a kind of "strong, synchronic, emergentist infinitism" (Aikin 2011: 72). So, let us see how the emergentist conception works with impure infinitism. Notice that the non-doxastic support is not a regress ender, so if there are series of propositions where each succeeding proposition is justified because its predecessor is, even where one of the propositions in the series integrates the non-doxastic support, the series will nonetheless run afoul of IP2. Giving that we deny the transmission conception, then the emergentist conception is an appropriate alternative. So, let us assume that each of the reasons in the series, p, q, r, s, and t are justified because justification emerges in the series as the series lengthens. This way, each proposition in the series starting from $\mathrm{p}$ could be independently justified and considered as basic propositions. ${ }^{9}$ So the infinite regress of reasons is made redundant by this series of basic beliefs. The very idea of an impeded regress of justification seems to me inimical to any version of infinitist theory of justification.

Finally, P3 seems to me a non-starter because all the propositions in the series cannot integrate a non-doxastic element. As Oakley succinct-

${ }^{9}$ Oakley invokes a similar argument against Klein's emergentist conception and concludes that Klein's version of infinitism collapses into a kind of foundationalism. 
ly remarks "it is impossible that each of the infinite chains of reasons should be matched at every point by an infinite number of non-doxastic input" (Oakley 2017: 17). The result is that since the non-doxastic support is not transmissible, only the proposition that incorporates the non-doxastic support will circumvent the MPR; others in the series cannot because they have not been "infested" with the non-doxastic support. So, impure infinitism fails to answer the MPR. The alternative is to assume the transmission requirement which I have pointed out is not feasible.

As it can be seen from the foregoing analysis, neither of these proposals appears plausible enough to salvage impure infinitism from possessing justification conferring status without losing its moorings with infinitism. On this account, one notes that only two options are available to Aikin: either he admits that strong impure infinitism is justification affording or he does not. Suppose he admits that strong impure infinitism is justification affording. In that case, the JAA is incoherent because JAA alone is an insufficient condition for a justification affording regress (this is based on the assumption indicated earlier that non-inferential support is not a regress ender). On the other hand, if it is not justification affording, then JAA with another requirement will be jointly necessary and sufficient for a justification affording regress, which may undermine the regress of justification. From all indications, by JAA Aikin requires that strong impure infinitism will yield a justification affording regress. The overall implication is that he succumbs in part to the challenge in IP1 that impure infinitism cannot generate a justification affording regress without undermining the regress of justification. Thus, if Aikin requires a justification affording regress for strong impure infinitism, he must admit that such intervention will undermine the infinitist regress of justification on the one hand, and on the other hand, he must accept that impure infinitism does not solve the MPR argument. It appears to me there is no way out of this problem.

\section{Conclusion}

The difficulty that beset Aikin's version of infinitism is apparent from his endorsement of non-doxastic support as a non-regress ender so that the theory may not stray out of the theoretical parameters of infinitism. But this problem generates more difficulties as an attempt to salvage epistemic infinitism from this clutter commits him to either undermining the regress of justification or evading the MPR argument. Aikin's master thesis is that the inferential chain with non-doxastic support is capable of conferring justification to a series of infinite and non-repeating series of reasons. This, however, is a mistake because Aikin notes that the non-doxastic support does not end the regress. So, strong impure infinitism does not possess a justification conferring property after all. Alternatively, to ensure that an inferential chain with nondoxastic support can confer justification in a series of reasons, one may 
need to introduce another requirement in addition to the inferential chain and the doxastic support for a justification conferral regress. But this, as seen in the foregoing narrative, will undermine the regress of justification. My argument is a vindication of Cling's argument that it is not possible for one to be an impure infinitist of the type Aikin envisages without undermining the infinitist regress of reasons.

\section{References}

Aikin, S. F. 2005. "Who is afraid of epistemology's regress problem?" Philosophical Studies 126 (2): 191-217.

Aikin, S. F. 2008. "Meta-epistemology and the varieties of epistemic infinitism." Synthese 163 (2): 175-185.

Aikin, S. F. 2011. Epistemology and the Regress Problem. London: Routledge.

Aikin, S. F. 2014. "Knowing better, cognitive command, and epistemic infinitism." In J. Turri and P. Klein (eds.). Ad infinitum: New Essays on epistemic infinitism. Oxford: Oxford University Press: 19-36.

Bonjour, L. 1985. The structure of empirical justification. Cambridge: Harvard University Press.

Cling, A. D. 2004. "The trouble with infinitism." Synthese 138 (1): 101-123.

Cornman, J. 1977. "Foundational versus non-foundational theories of empirical justification." American Philosophical Quarterly 14: 287-297.

Haack, S. 1993. Evidence and inquiry: A pragmatist reconstruction of epistemology. New York: Prometheus Books.

Herzberg, F. 2014. "The dialectics of infinitism and coherentism: Inferential justification vs holism and coherence." Synthese 191 (4): 701-723.

Fantl, J. 2012. "Review of Scott F. Aikin, epistemology and the regress problem." International Journal for the Study of Skepticism 2: 157-60.

Klein, P. 1999. "Human knowledge and infinite regress of reasons." Nous 13: 297-325.

Oakley, T. 2017. "The reductio argument against epistemic infinitism." Synthese. doi.org/10.1007/s11229-017-1629-z

Post, J. 1980. "Infinite regress of justification and explanation." Philosophical Studies 38: 31-52. 
